\title{
ORGANIZING THE ESTONIAN PHYSICIANS' NUTRITIONAL AND DIETETICS SOCIETY IN TARTU UNIVERSITY HOSPITAL
}

\author{
LIIDIA KIISK \\ Estonian Physicians' Nutritional and Dietetics Society \\ Tartu University Hospital, Food Service, Tartu, Estonia
}

\begin{abstract}
Along with everyday clinical work, many nurses and physicians are dealing with clinical nutrition - counselling of patients, nutrition research and cooperation with specialists. It is essential to organise the clinical nutrition of inpatients, outpatients and home-care patients. Patients with chronic diseases and their carers expect increasingly profound information and guidelines about their nutrition from their attending physicians or department nurses and later at home - for this, specific guidelines are needed.

An initiative group of physicians at Tartu University Hospital founded the Estonian Physicians' Nutritional and Dietetics Society. The aims of the Estonian Physicians' Nutritional and Dietetics Society are development of cooperation and information exchange with specialists in different areas, development and conducting of continuing education programmes in dietetics in cooperation with the Centre for Continuing Medical Education at the University of Tartu. The terminology of dietetics needs unification and updating. Disease-specific clinical nutrition guidelines have to be compiled and published.
\end{abstract}

Keywords: clinical nutrition; dietetics; clinical nutritionist; nutrition care programme

\section{CLINICAL NUTRITION}

Clinical nutrition plays an important role in patients' nutrition care process in medicine. Clinical nutrition is an interdisciplinary speciality and a significant 
part of treatment which includes everyday cooperation between the medical staff and the food service provider. According to the Estonian Qualifications Authority, there are many public health or community dietitians in Estonia, but they do not prescribe diets in the case of illnesses. Thus, nutrition consultants without medical education are not competent to counsel patients with chronic diseases.

In Finland, clinical nutrition can be studied at the Institute of Public Health and Clinical Nutrition in Kuopio at three levels: bachelor's degree in clinical nutrition (3 years of studies), master's degree in clinical nutrition ( $3+2$ years of studies) and doctoral programmes in nutrition and health, and in the School of Medicine. Within their speciality, clinical nutrition has been and must be practised by attending physicians who, if necessary, consult trained clinical dietitians or food service dietitians or refer their patients to them.

Nowadays, the number of patients with multiple morbidities is increasing. Half of the adult population has been found to suffer from one or several chronic diseases. Cardiovascular diseases and cancerous tumours constitute $46 \%$ of all chronic diseases [1]. Additionally, the prevalence of diabetes, adiposity and chronic kidney disease is growing, causing an increasing need for adequate nutritional counselling [2]. In the treatment of multimorbid patients, clinical nutrition plays an important role where clinical nutrition specialists contribute in many ways to individual counselling of chronic patients. In addition to everyday work in clinical nutrition, diet nurses and physicians do nutrition research and, in cooperation with other specialists, organise clinical nutrition in medical institutions. In many hospitals, expert groups or clinical nutrition teams have been created, which consist of specialists in various diseases, clinical dietitians and food service dietitians.

Patients with chronic diseases expect increasingly profound information and nutrition guidelines from attending doctors or department nurses, and later at home - therefore, specific guidelines are urgently needed. Clinical nutrition relies on internationally recognised guidelines which are based on diagnoses and secure the preservation and development of the academic level in clinical nutrition [4]. In clinical nutrition, we have primarily followed the activities of academic societies of the Nordic countries (https://ncpt.webauthor. com); we also use the treatment guides of ESPEN (The European Society for Clinical Nutrition and Metabolism - diagnostic criteria. http://www.espen.org/ education/espen-guidelines).

The European Federation of the Associations of Dietitians (EFAD) has indicated an increasing interest among European dietitians concerning a 
standardised language for documentation of dietetic care. Nutrition care process terminology consists of four steps: nutritional assessment, nutrition diagnosis, nutrition intervention, and nutrition monitoring and evaluation [4]. Rossi and al. described the implementation of an electronic system of nutrition care process and compared it with a paper-based system in a population receiving haemodialysis. This resulted in significant improvements in the efficiency of nutrition care and effectiveness related to patient outcomes [5]. Malnutrition/undernutrition, overweight, obesity, micronutrient abnormalities and re-feeding syndrome are clear nutritional disorders, whereas sarcopenia and frailty are nutrition-related conditions with complex and multiple pathogenic backgrounds [6].

\section{ESTONIAN PHYSICIANS' NUTRITIONAL AND DIETETICS SOCIETY}

The Estonian Physicians' Nutritional and Dietetics Society was founded by an initiative group consisting of physicians of different specialities at Tartu University Hospital on 31 March 2017. The founding members of the Society were physicians of different specialities like a physician of internal medicine, a nephrologist, an endocrinologist, an oncologist, a paediatrician, a dietitian and other. The main aims of the Estonian Physicians' Nutritional and Dietetics Society are continuous development and coordination of strategies, development of dietetics as a speciality, preservation and upgrading the professional standards of physicians dealing with dietetics, advancement of mutual communication and interdisciplinary cooperation in medical institutions, development and teaching of programmes of continuing education in dietetics in cooperation with the Centre for Continuing Medical Education at the University of Tartu. The terminology of dietetics needs unification and updating. Clinical nutrition guidelines for different diseases have to be compiled and published. If international guidelines exist, they can be translated and applied by Estonian medical institutions.

To achieve its aims, the Estonian Physicians Nutritional and Dietetics Society conducts various academic activities which consider the viewpoints of evidence-based medicine in organising clinical nutrition at university hospitals. It is essential to develop cooperation and exchange information with specialists of different specialities of the Faculty of Medicine at the University of Tartu in research and teaching. It is necessary to arrange continuing education programmes in dietetics in cooperation with the Centre for Continuing Medical Education at the University of Tartu. Unification and updating of terminology and structure of dietetics at Estonian medical institutions needs further 
attention. Guidelines need to be translated, original guidelines and other publications necessary for the speciality have to be compiled and published.

\section{ORGANISING A CLINICAL NUTRITION EXPERT GROUP AT A MEDICAL INSTITUTION}

The need for founding an expert group of clinical nutrition has also become topical at Tartu University Hospital. Nowadays, one person is unable to meet the need for clinical nutrition at a large hospital, and therefore, the dietary nurses, hygienists, logopedists and physicians with a special interest in clinical nutrition who take care of the treatment quality of patients have been of great help. These colleagues from different departments have been the initiators of the clinical nutrition expert group. The members of the expert group can help to advance the organisation of contemporary individual clinical nutrition for our patients.

At Tartu University Hospital, the description of the process of individual counselling, dietological terminology, monitoring of nutrition, methodology of measurements, assessment, collection and analysis of data in treatment of in- and outpatients needs unification and development. The members of the clinical nutrition expert group can contribute to coordination of clinical nutrition activities which include updating the system of diets used in medical institutions, support to counselling of in- and outpatients, continuous counselling and training of medical staff, cooperation between the clinics and food service providers, compilation and approval of information materials and guidelines, further cooperation with specialists of different specialities. Within the medical institution, an interdisciplinary expert group consisting of specialists of different specialities (especially intensive care, surgery, gastroenterology, nephrology, oncology, paediatrics, rehabilitation) will be helpful.

Raising the awareness of the staff of the structural units on clinical and healthy nutrition supports, in its turn, rational choices in the case of different diseases, ensuring the patients' wellbeing and a health service with maximum benefit and minimal risk.

\section{ACKNOWLEDGMENTS}

The author thanks Professor Mai Rosenberg, Tartu University Hospital, all colleagues from the Estonian Physicians' Nutritional and Dietetics Society, and language editor Ilmar Anvelt. 


\section{REFERENCES}

1. Centers for Disease Control and Prevention. (2014). Leading causes of death and numbers of deaths, by sex, race, and Hispanic origin: United States, 1980 and 2014. Health, United States.

2. Gomes F., Schuetz P., Bounoure L., Austin P., Ballesteros-Pomar M., Cederholm T., Fletcher J., Laviano A., Norman K., Poulia K.A., Ravasco P., Schneider S.M., Stanga Z., Weekes C.E., Bischoff S.C. (2018). ESPEN guidelines on nutritional support for polymorbid internal medicine patients. Clinical Nutrition, 37(1), 336-353.

3. Ryan K.J., Casas J.M., Mash L.E., McLellan S.L., Lloyd L.E., Stinear J.W., Plank L.D., Collins M.G. (2014). The effect of intensive nutrition interventions on weight gain after kidney transplantation: protocol of a randomised controlled trial. BioMed Central Nephrology, 9, 1-9.

4. Lövestam, E. (2015). Dietetic documentation. Content, language and the meaning of standardization in Swedish dietitians' patient record notes. Digital Comprehensive Summaries of Uppsala Dissertations from the Faculty of Social Sciences, 1-88.

5. Rossi, M., Campbell, K. L., Ferguson, M. (2014). Implementation of the nutrition care process and international dietetics and nutrition terminology in a singlecenter hemodialysis unit: comparing paper vs electronic records. Journal of the Academy of Nutrition and Dietetics, 114 (1), 124-130.

6. Cederholm T., Barazzoni R., Austin P., Ballmer P., Biolo G., Bischoff S.C., Compher C., Correia I., Higashiquchi T., Holst M., Jensen G.L., Malone A., Muscaritoli M., Nyulasi I., Pirlich M., Rothenberg E., Schindler K., Schneider S.M., de van der Schueren M.A.E., Sieber C., Valentini L., Yu J.C., Van Gossum A., Singer P. (2017). ESPEN guidelines on definitions and terminology of clinical nutrition (2017). Clinical Nutrition, 36 (1), 49-64.

\section{Address for correspondence:}

Liidia Kiisk

Tartu University Hospital

L. Puusepa 8, Tartu, Estonia

E-mail: Liidia.Kiisk@kliinikum.ee 